\title{
Synthesis of Silver Doped CdSe Thin Film by Triethanolamine Complex Method at Room Temperature
}

\author{
PARESH SAHA* and JATINDRA NATH GANGULI \\ Department of Chemistry, Gauhati University, Guwahati-781014, India \\ pareshsaha8@gmail.com
}

Received 3 September 2017 / Accepted 20 September 2017

\begin{abstract}
The silver doped thin film of CdSe has been deposited onto clean glass substrate by using chemical bath deposition technique.CdSe thin film doped with silver showed well defined peak with narrow width. From the XRD pattern, it was observed that the deposited thin film has both hexagonal (002) $\mathrm{H}$ and cubic phase (111) $\mathrm{C}$ with preferred orientation in the (111) direction. Absorption spectra of this film have been recorded using spectrophotometer. The thickness of the film has been determined by gravimetric method. The energy band gap has been calculated using Tauc's method. It is found that energy band gap of Ag doped CdSe thin film is $1.74 \mathrm{eV}$.
\end{abstract}

Keywords: Silver doped CdSe thin film, Energy band gap, TEA, Triethanolamine complex

\section{Introduction}

Thin films of II-VI compounds have been widely investigated primarily because of their electronic, optical and optoelectronic applications. II-VI compound semiconductors have a band gap between 1-3 eV, which falls in the visible region and these semiconducting materials are used worldwide in optoelectronic devices. CdSe is one of such compound in this group and its physical properties have been constantly investigated during recent years for both fundamental and practical aims. It's interesting properties make them suitable for many potential applications in a variety of solid state devices such as solar cell, high efficiency thin film transistors, lightemitting diodes, electron-beam pumped lasers and electroluminescent devices $e^{1 c^{1-3}}$.

In the recent years, major attention has been given to the investigation of optical and electrical properties of $\mathrm{CdSe}$ thin films in order to improve the performance of the device and also for finding new application ${ }^{4-8}$. These properties of CdSe are very sensitive to deposition condition and to the technique used. CdSe thin film has been prepared using a variety of methods including sputtering, spray pyrolysis, electro-deposition and thermal evaporation under high vacuum ${ }^{9,10}$. In view of this, the present study deals with preparation of silver doped of CdSe thin films by Chemical Bath Deposition (CBD) method at room temperature under basic condition on glass substrates. The CBD is considered to be an easy, simple and low cost method. 


\section{Experimental}

Cadmium sulphate was purchased from LOBA Chemicals. 30\% ammonia solution, silver nitrate and triethanolamine were procured from Merck. All chemicals were used as purchased. Sodium selenosulphite $\left(\mathrm{Na}_{2} \mathrm{SeSO}_{3}\right)$ was prepared by heating selenium powder with a solution of sodium sulphite $\left(\mathrm{Na}_{2} \mathrm{SO}_{3}\right)$ in water at $90{ }^{\circ} \mathrm{C}$ with constant stirring.

\section{Deposition of CdSe thin film}

A $30 \mathrm{~mL}$ of $0.5 \mathrm{M}$ cadmium sulphate $\left[\mathrm{CdSO}_{4}\right]$ solution was mixed with $1 \mathrm{~mL}$ of $0.001 \mathrm{M} \mathrm{AgNO}_{3}$ solution. Then $30 \%$ ammonia solution was added to this mixture. A white turbidity appears which was dissolved in excess of ammonia solution. After dissolving the turbidity $30 \mathrm{~mL}$ of $0.5 \mathrm{M}$ sodium selenosulphite was mixed with the solution. With this $30 \mathrm{~mL}$ triethanolamine was mixed with constant stirring. Then the solution was transferred to a $250 \mathrm{~mL}$ beaker in which glass plate were suspended horizontally. The system was kept at room temperature without disturbing. The Ag doped thin film of CdSe has been deposited on clean glass plate after $48 \mathrm{~h}$.

\section{Characterization}

UV-Vis spectra were recorded by using a U-4100 spectrophotometer (Hitachi). X-ray diffraction (XRD) patterns were recorded on SIEMENS D5005 X-ray diffractometer with $\mathrm{Cu} \mathrm{K} \alpha$ radiation. The film thickness varied with deposition time. The thickness of the film was measured by weight difference method assuming the density of the deposited film to be same as that of the bulk ${ }^{11}$.

\section{Results and Discussion}

XRD studies

The CdSe thin film doped with silver showed well defined peak with narrow width indicated increase in crystalline nature (Figure 1). The presence of $\mathrm{CdSe}$ and $\mathrm{AgSe}$ peaks were confirmed by comparing with JCPDS Card No. 019- 0191for CdSe and JCPDS Card No.760135 for AgSe. The peaks positions due to CdSe and AgSe were also shown in the XRD pattern. From the XRD pattern, it was observed that the deposited thin film has both hexagonal (002) $\mathrm{H}$ and cubic phase (111) $\mathrm{C}$ with preferred orientation in the (111) direction.

\section{Optical properties}

The absorption spectra of CdSe thin film have been recorded over wavelength range 400 to $850 \mathrm{~nm}$ using a U-4100 spectrophotometer at room temperature. Figure 2 shows the absorption spectra of Ag doped CdSe thin film.

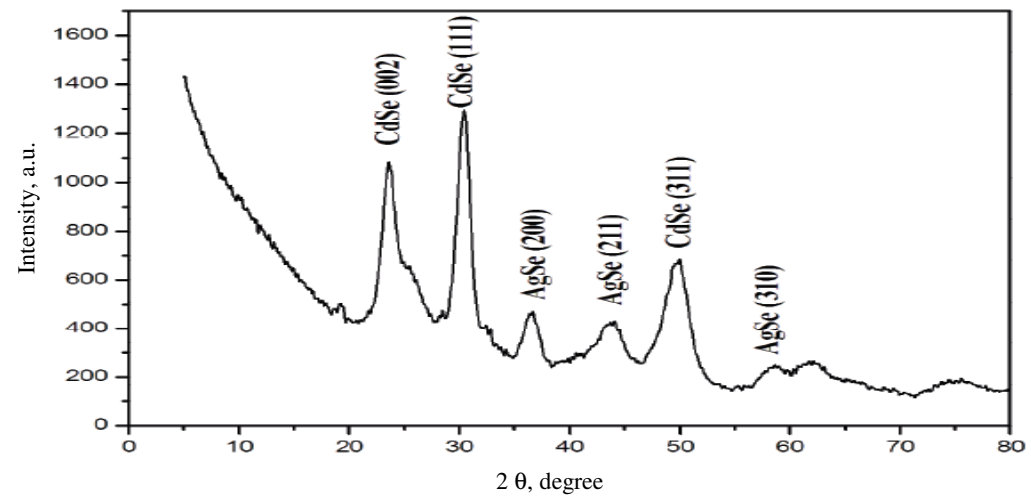

Figure 1. X-Ray diffraction pattern of Ag doped CdSe thin film 
It is observed that the absorption coefficient is high at lower wavelength and decreases sharply below a certain wavelength for CdSe thin film. The energy band gap was determined using absorption spectra with the help of Tauc relation ${ }^{12}$. Using this relation, a graph is plotted between the square of $(\alpha h v)$ and $h v$ to obtain a straight line (Figure 3). The extrapolation of straight line to $(\alpha h v)^{2}=0$ axis gives the value of the band gap. The energy band gap of this sample is $1.74 \mathrm{eV}$ which is smaller than the CdSe thin film prepared without doping and nearly the bulk value. The observation was also supported by the XRD results which indicated the increase in crystalline size as compared to as deposited CdSe thin film.

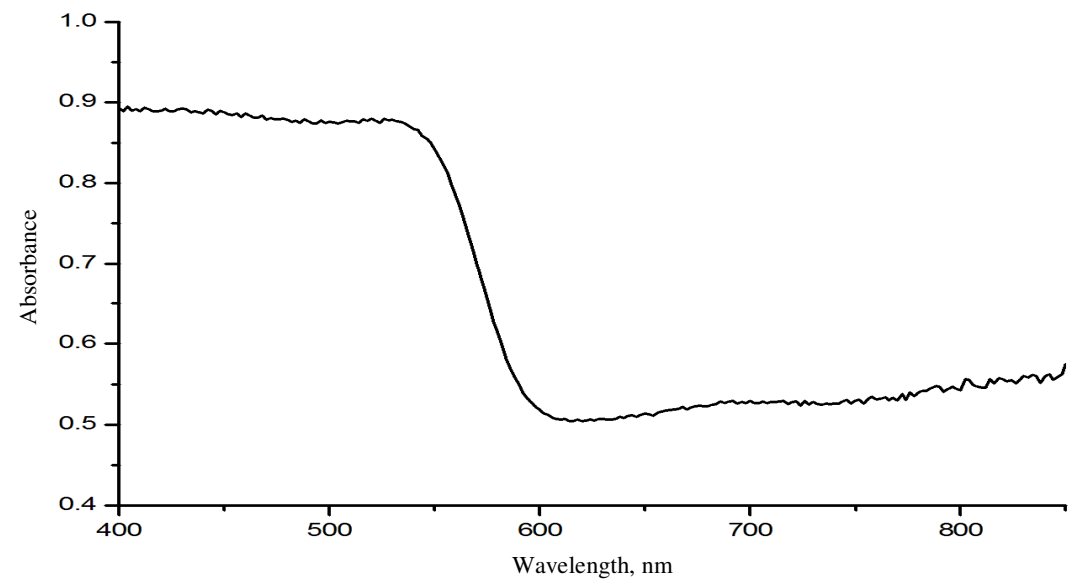

Figure 2. Absorption spectra of Ag doped CdSe thin film

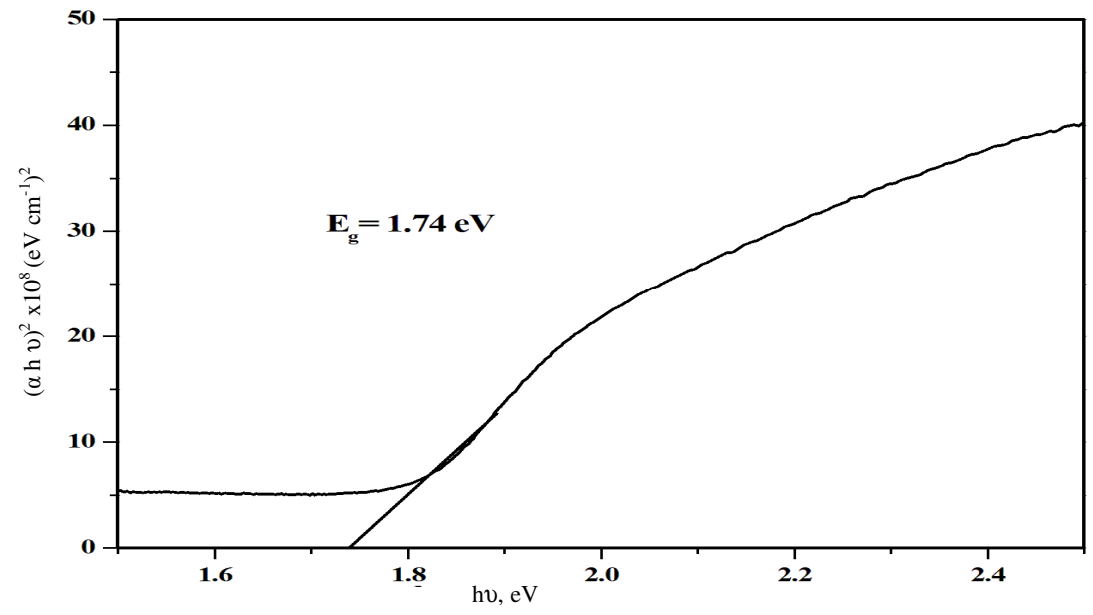

Figure 3. Plot of energy band gap $(\alpha h v)^{2} v s$. photon energy( hv) of Ag-doped CdSe thin film

\section{Surface morphology and elemental analysis}

The EDX and SEM micrographs were shown in Figure 4 and 5.The EDX analysis showed the presence of $\mathrm{Ag}$ atom in the deposited CdSe thin film. Also it was seen that due to silver doping the film became nonstoichiometric with $\mathrm{Cd}$ :Se ratio 57.04:42.54.The atomic percentage of silver was found to be of $0.42 \%$. 


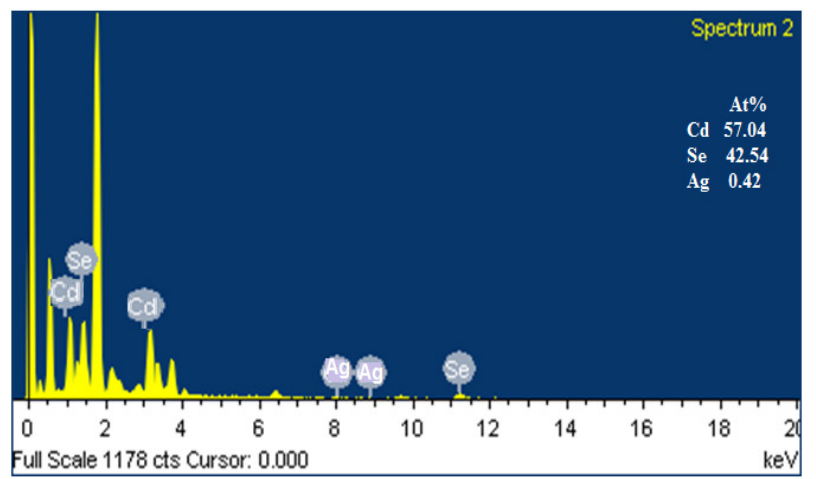

Figure 4. EDX spectrum of Ag doped CdSe thin film

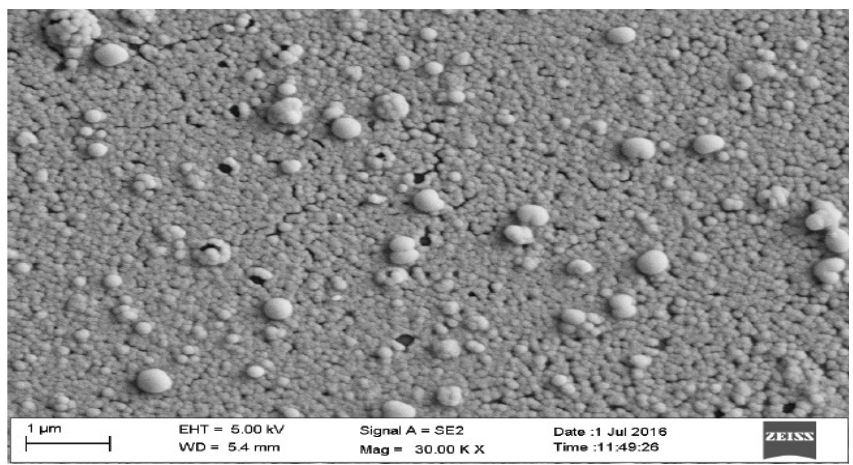

Figure 5. SEM micrograph of Ag doped CdSe thin film

\section{Conclusion}

The XRD study of silver doped CdSe thin film at room temperature revealed that the film has cubic phase with (111) plane as the preferred orientation. Doping of silver did not cause any phase changes but improved crystallinity as compared to the undoped room temperature deposited CdSe thin film ${ }^{11}$. The band gap energy decreased from $2.35 \mathrm{eV}$ to $1.74 \mathrm{eV}$ after silver doping. The presence of silver in the CdSe thin film was confirmed by EDX analysis.

\section{Acknowledgement}

The authors are grateful to Gauhati University, Assam for the assistance for this work. The authors are also thankful to SAIF, Gauhati University for XRD analysis and IASST (Guwahati) for SEM analysis.

\section{References}

1. Bouroushian M, Loizos Z, Syrellis N and Maurin G, Thin Solid Films, 1993, 10(2), 229-242; DOI:10.1016/0040-6090(72)90190-3

2. Shaw G A and Parkin I P, Inorg Chem., 2001, 40, 6940-6947;

DOI:10.1021/ic010648s

3. Baban C, Rusu G I and Prepelita P, J Optoelectronics Adv Mater., 2005, 7(2), 817-821.

4. Oduor O and Gould R D, Thin Solid Films, 1995, 270(1-2), 387-390;

DOI:10.1016/0040-6090(95)06930-5 1998, 317(1-2), 409-412; DOI:10.1016/S00406090(97)00575-0 
5. Mohanchandra K P and Uchil J, Thin Solid Films, 1997, 305, 124-129;

DOI:10.1016/S0040-6090(97)00188-0; J Appl Phys., 1998, 84(2), 306;

DOI: $10.1063 / 1.368028$

6. Lee M J and Shis-Chung Lee, Solid State Electronics, 1999, 43(4), 833-838;

DOI:10.1016/S0038-1101(99)00007-6

7. Samanta D, Samanta B, Chaudhuri A K, Ghorai S and Pal U, Semicond Sci Technol., 1996, 11, 548-553.

8. Pal U, Samata D, Ghorai S and Chaudhuri A K, J Appl Phys., 1993, 74(10), 6368-

6374; DOI: 10.1063/1.355161

9. Chopra K L and Das S R, Thin Film Solar Cells (Plenum Press, New York-London, 1983, 143-150.

10. Rouleau C M and Lowndes D H, Appl Surf Sci., 1998, 127-129, 418-424;

DOI:10.1016/S0169-4332(97)00666-1

11. Saha Paresh, Ganguli J N and Sarma S N, Chem Sci Trans., 2016, 5(3), 657-660; DOI:10.7598/cst2016.1259

12. Cullity B D, Elements of x-ray diffraction, Addison Wesley, Massachusetts, London, 1959. 